\title{
Association between surgical volumes and real-world healthcare cost when using a mesh capturing device for pelvic organ prolapse: A 5-years comparison between single- versus multicenter use
}

\author{
Edward Morcos ${ }^{1,2} \cdot$ Christian Falconer $^{1} \cdot$ Emilie Toresson Grip $^{3} \cdot$ Kirk Geale $^{3,4}$ - Katarina Hellgren ${ }^{1}$. \\ Georgios Poutakidis ${ }^{1}$ - Daniel Altman ${ }^{5,6}$
}

Received: 24 November 2020 / Accepted: 10 January 2021 / Published online: 26 February 2021

(C) The Author(s) 2021

\begin{abstract}
Introduction and hypothesis The aim of this study was to evaluate whether high surgical volume at a single center was associated with lower healthcare costs compared to lower surgical volume in a multicenter setting.

Methods All patients had symptomatic and anatomical apical prolapse (POP-Q $\geq$ stage II) with or without cystocele and were operated on by a standard surgical procedure using the Uphold mesh. Data on time of resource use in terms of surgery time, hospital stay and re-interventions across 5 years were compared between the single center (97 patients) and multicenter (173 patients, at 24 clinics). Unit costs for surgical time, inpatient and outpatient visits were extracted from the single-center hospital's operation analysis program and prime production cost. Total costs were estimated for primary surgery and during 5-year follow-up.

Results Costs for primary surgery were comparable between the single and the multicenter $(\$ 13,561 \pm 2688$ and $\$ 13,867 \pm 1177$, $P=0.29$ ). Follow-up costs 5 years after primary surgery were 2.8 times higher at the multicenter than single center $(\$ 3262$ vs. $\$ 1149, P<0.001)$. Mean cost per patient over 5 years was significantly lower at the single than multicenter [ $\$ 14,710(\mathrm{CI}$ : $14,168-15,252)$ vs. $\$ 17,128$ (CI: 16,952-17,305), $P<0.001)]$.

Conclusions Using a mesh kit for apical pelvic organ prolapse in a high surgical volume center was associated with reduced healthcare costs compared with a lower volume multiple-site setting. The cost reduction at the high surgical volume center increased over time because of lower surgical and medical re-intervention rates for postoperative complications and recurrence.
\end{abstract}

Keywords Health-care costs · Surgery volume $\cdot$ Vaginal prolapse mesh $\cdot$ Centralization

Edward Morcos

edward.morcos@sll.se

1 Department of Clinical Sciences, Division of Obstetrics and Gynecology, Karolinska Institutet Danderyd Hospital, SE-171 77 Stockholm, Sweden

2 Department of Gynecology \& Obstetrics, Karolinska Institutet, Danderyd University Hospital, Danderyd, 182 88 Stockholm, Sweden

3 Quantify Research, Stockholm, Sweden

4 Department of Public Health and Clinical Medicine, Umeå University, Umeå, Sweden

5 Department of Women's and Children's Health, Uppsala University, Uppsala, Sweden

6 Stockholm Urogynecological Clinic, Stockholm, Sweden

\section{Introduction}

Long-term assessments of reconstructive surgery using the transvaginal Uphold ${ }^{\text {Lite }}$ mesh kit to suspend the apical vaginal segment have shown the procedure to improve pelvic organ prolapse symptoms and have high effectiveness in restoring the vaginal anatomy [1-4]. Although the $\mathrm{Uphold}^{\mathrm{Lite}}$ mesh kit is no longer commercially available, ongoing research on the use of biomaterial implants is encouraged to continue by regulatory authorities in order to collect long-term safety and efficacy data. Accumulating evidence suggests that use of vaginal mesh is efficacious with relatively low rates of complications when performed at high surgical volume centers [1-8]. High surgical volumes lower the perioperative complication rates and re-operation rates compared to sites with low surgical volumes [5-8].

As healthcare expenditures are rising globally, wellinformed decisions on allocation of scarce resources to optimize provision of healthcare, quality of treatment and patient 
safety are increasingly important [9]. Given that costs of inpatient care alone constitute approximately $25 \%$ of all health expenditures in the Nordic countries (https://www.oecdilibrary.org/social-issues-migration-health/health-at-a-glance2019 4dd50c09-en), improving surgical cost-effectiveness is of particular relevance. Centralization of surgical procedures includes concentration of resources, including staff, material and knowledge, allowing for high surgical volumes at a single site. Advocates of surgical centralization suggest that in a particular field the concentration of resources to highvolume centers may lead to improved quality of care and potentially increased economic efficiency [10-13]. The aim of this study was to investigate the difference in healthcare costs between a high surgical volume single site and low surgical volume multicenter sites using a mesh capturing device in a standardized surgical procedure.

\section{Materials and methods}

\section{Patients and surgery centers}

Data from two previously published cohort studies comparing outcomes from high surgical volume at a single-center to low surgical volumes in a multicenter setting was used [1, 3, 6, 14]. At the single center, 115 patients were operated on by two experienced urogynecological surgeons from January 2012December 2014 at the Department of Obstetrics and Gynecology, Danderyd Hospital, Stockholm, Sweden. Two hundred seven patients were operated on during 2012 at the multicenter setting by 26 surgeons at 24 centers spread across four countries: Sweden (11 centers), Finland (4 centers), Denmark (4 centers) and Norway (5 centers) [14]. All surgeons at the single- and multicenter sites were at a senior consultant level and obtained standardized pre-trial hands-on training. Surgery data, outcomes and re-interventions for the patient cohorts over 5 years were previously published in detail $[1,3,6,14]$. Ninety-seven patients operated on by two surgeons (E.M. 57 and C.F. 40) were available for the cost evaluation at the single center and were compared to 173 patients operated on by 26 surgeons (range 1-13 per surgeon) at the multicenter.

All patients had symptomatic and quantified apical segment prolapse (POP-Q $\geq$ stage 2 ) with or without anterior wall prolapse according to the pelvic organ prolapse quantification (POP-Q) system [15]. Using a standardized surgical procedure with a capturing device, the Uphold transvaginal mesh was placed to suspend the apical vaginal segment $[6,14]$. POP-Q stage 0 or 1 in the apical compartment was considered an optimal anatomical outcome and was the primary outcome measure for the analysis.

As previously reported, the study protocol was almost identical for both studies, and neither study was blinded $[6$,
14]. Patients with current or previously treated pelvic organ cancer and cervical elongation were excluded, as were those with severe rheumatic disease, insulin-treated diabetes mellitus, connective tissue disorders, current systemic steroid treatment or urinary incontinence. Patient follow-up occurred 1 and 5 years after surgery in the multicenter setting study and after 2 and 5 years in the single-center study. There were no restrictions on weight, parity, menopausal status or previous surgery in either studies. Index date was considered the date of primary surgery using the Uphold Mesh.

Resource use was estimated based on previously collected data on time of surgery, recovery care time, type of anesthesia, length of hospital stay, outpatient visits and prescription drug use. Medical resource use was extracted from previously collected data for primary surgery and for medical and surgical re-interventions over a 5 -year period $[1,3,6,14]$. Resource use for primary surgical complications including urinary tract infection and hematoma, etc., were based on required medical treatment at an out-clinic or hospital re-admission, e.g., for embolization of the uterine artery $[6,14]$.

\section{Cost estimation}

Costs per surgical minute (30 USD), inpatient day $(1,024$ USD) and outpatient visit (362 USD) were estimated based on charges derived from the single-center internal analysis system fee-for-service schedules, prime production cost and real prices from negotiated agreements for equipment and disposables. For consistency, the same unit costs were used to estimate the total cost of resource use from all sites in all countries at the multicenter. Unit costs included surgeon and personal salaries, equipment and supplies, mesh kit, nursing services, prescriptions, room-related services, local rent, laboratory tests and radiological examination. Costs of pharmacy-dispensed medication were based on pharmacy retail prices in Sweden (https://www.fass.se/LIF/startpage) and used to estimate the costs of pharmacy-dispensed medications in all countries. Costs of hospital-administered drugs were based on costs provided by the single-center main pharmacy supplier and used for all countries.

Total healthcare costs for the comparative analysis between the single and the multicenter were calculated by multiplying the common unit costs with site-specific resource use for surgery and recovery time, hospital stays, outpatient visits and pharmacy-dispensed medications. Costs were estimated separately for primary surgery and for the follow-up time up to 5 years. Indirect costs capturing differences in productivity losses between patients treated in single or multicenter settings, for example, were not available for inclusion, nor were certain overheads.

To analyze whether the type of anesthesia was associated with surgery time and thus a potential confounder in the comparison between the single- and multicenter sites, operation 
time data from the single center were analyzed and divided into two groups based on the type of anesthesia: spinal or general anesthesia. Time (minutes) at the operation ward included the operating room time and time at the recovery unit after surgery until the patient was discharged from the operation ward to an in-patient ward (hospital stay). Operating room time was divided into preparation time before anesthesia start, interventional anesthetic time before surgery, surgery time and anesthetic time after surgery. Time spent at the recovery unit was considered as the time from patient discharge from the operation room to the recovery unit until patient discharge to the in-patient department (hospital stay).

\section{Statistical analyses}

IBM $^{\circledR}$ SPSS $^{\circledR}$ Statistics (version 25, Chicago, IL, USA, 2017) was used for all statistical analyses performed. Mean differences in costs and resource use between the single and the multicenter were evaluated using independent sample twosided t-tests. Chi-squared test of independence was used to test the statistical difference between nominal data. Repeated measures ANOVA was used to evaluate differences over time within groups and to compare between groups. $P$-values $<$ 0.05 were considered statistically significant. We used multiple regression stratified analysis of covariance (ANCOVA) to investigate whether patient's socioeconomic, medical and surgery characteristics were predictive of costs. Stratified analysis was also performed to evaluate whether the impact of regressors on costs differs between the sites, using standardized beta-coefficient values. Observations with missing information were dropped, and there was no imputation of missing data. Number of observations is shown for all results.

\section{Results}

\section{Demographics}

Patients medical, socioeconomic and surgery characteristics are illustrated in detail in Table 1. There was a significant difference at the education level to the favor of the single center $(P<0.001)$. Use of spinal anesthesia was more common at the single center [82/97 (84.5\%) vs. 87/173 (50.3\%), $P<0.001]$, whereas general anesthesia was more commonly used at the multicenter [86/173 (49.7\%) vs. $15 / 97$ (15.5), $P<0.001]$. Operating time was longer at the single center $(63.5 \pm 14.3$ vs. $56.5 \pm 18.4, P=0.001)$ probably because of the higher rate of previous prolapse recurrence surgery [57/97 (58.8\%) vs. 66/173 (38.2\%), $P=0.001]$. Hospital stay was shorter at the single center $(1.3 \pm 0.63$ vs. $1.7 \pm 0.96$, $P<0.001)$.

\section{Assessing diverging anesthesia routines in single and multicenter sites}

Operation and recovery time by type of anesthesia (spinal and general) at the single center is presented in Table 2. The total

Table 1 Demographic, medical, socioeconomic and surgery characteristics for the single and multicenter settings

\begin{tabular}{|c|c|c|c|c|c|}
\hline & \multicolumn{2}{|l|}{ Single center } & \multicolumn{2}{|l|}{ Multicenter } & \multirow[t]{2}{*}{$P$-value } \\
\hline & Mean \pm SD & $n$ & Mean \pm SD & $n$ & \\
\hline Age $(\leq 65,>65$ year $)$ & $57.7 \pm 7.6(45.4 \%), 73 \pm 4.3(54.6 \%)$ & 97 & $58.2 \pm 6.8(43.8 \%), 72.6 \pm 5.3(56.2 \%)$ & 169 & 0.804 \\
\hline BMI & $25.7 \pm 3.6$ & 81 & $25.8 \pm 3.01$ & 164 & 0.859 \\
\hline Vaginal deliveries & $2.4 \pm 1.3$ & 86 & $2.2 \pm 1.06$ & 166 & 0.160 \\
\hline Somatic diseases (none, CVS, other diseases) & $34(35.1 \%), 39(40.2 \%), 24(24.7 \%)$ & 86 & $60(34.7 \%), 75(43.4 \%), 38(22 \%)$ & 173 & 0.837 \\
\hline Physical training $(0,1-2,3-4$ times/week $)$ & $8(9.8 \%), 45(54.9 \%), 29(35.4 \%)$ & 82 & $16(9.9 \%), 96(59.6 \%), 49(30.4 \%)$ & 161 & 0.732 \\
\hline Job (in pension, working) & $57(67.1 \%), 28(32.9 \%)$ & 85 & $91(60.7 \%), 59(39.3 \%)$ & 150 & 0.330 \\
\hline $\begin{array}{l}\text { Education level (elementary, } \\
\text { upper secondary school, } \\
\text { university education 3-6 years) }\end{array}$ & $23(27.1 \%), 18(21.2 \%), 44(51.7 \%)$ & 85 & $58(34.9 \%), 64(38.6 \%), 44(26.5 \%)$ & 166 & $<0.001$ \\
\hline Annual income $(<\$ 29,000,>\$ 29,000 /$ year $)$ & $38(50.7 \%), 37(49.3 \%)$ & 75 & $64(41.3 \%),(58.7 \%)$ & 155 & 0.180 \\
\hline Pain (VAS 0-10) & $1.1 \pm 1.85$ & 88 & $1.0 \pm 1.61$ & 165 & 0.661 \\
\hline $\begin{array}{l}\text { Hysterectomy prior to } \\
\text { surgery vs. still having uterus }\end{array}$ & $17(17.5 \%), 80(82.5 \%)$ & 97 & $69(39.9 \%), 104(60.1 \%)$ & 173 & $<0.001$ \\
\hline Primary vs. recurrent prolapse surgery & $40(41.2 \%), 57(58.8 \%)$ & 97 & $107(61.8 \%), 66(38.2 \%)$ & 173 & 0.001 \\
\hline Anesthesia type (spinal, general) & $82(84.5 \%), 15(15.5 \%)$ & 97 & $87(50.3 \%), 86(49.7 \%)$ & 173 & $<0.001$ \\
\hline Operating time (min) & $63.5 \pm 14.3$ & 97 & $56.5 \pm 18.4$ & 173 & 0.001 \\
\hline Hospital stay $($ mean \pm SD) $(\leq 1,>1$ day $)$ & $1.3 \pm 0.6375(77.3 \%), 22(22.7 \%)$ & 97 & $1.7 \pm 0.9670(42.2 \%), 96(57.8 \%)$ & 166 & $<0.001<0.001$ \\
\hline
\end{tabular}

Independent sample two-sided t-test and chi-squared test of independence were used. $P<0.05$ was considered significant 
Table 2 Time data extracted for the primary surgery (minutes)

\begin{tabular}{|c|c|c|c|c|}
\hline & $\begin{array}{l}\text { Spinal anesthesia } \\
n=82\end{array}$ & $\begin{array}{l}\text { General anesthesia } \\
n=15\end{array}$ & $\begin{array}{l}\text { Full population } \\
\text { (spinal and general) } \\
n=97\end{array}$ & $\begin{array}{l}P \text {-value } \\
\text { (spinal vs. general) }\end{array}$ \\
\hline Operation theater time before anesthesia & $13 \pm 8$ (CI: $11-15)$ & $12 \pm 5$ (CI: 9-15) & $13 \pm 7$ (CI: 11-14) & 0.674 \\
\hline Interventional anesthesia time before surgery & $14 \pm 6$ (CI: $13-15)$ & $12 \pm 6$ (CI: 9-16) & $14 \pm 6$ (CI: 13-15) & 0.328 \\
\hline Surgery time & $63 \pm 14$ (CI: $60-66)$ & $68 \pm 16$ (CI: 59-77) & $64 \pm 14$ (CI: 61-66) & 0.210 \\
\hline Interventional anesthesia time after surgery & $14 \pm 5$ (CI: $13-15)$ & $18 \pm 6(\mathrm{CI}: 14-21)$ & $15 \pm 5$ (CI: $14-16)$ & 0.021 \\
\hline Total operation theater time & $104 \pm 23$ (CI: 100-108) & $110 \pm 23$ (CI: 97-123) & $105 \pm 19$ (CI: 101-109) & 0.283 \\
\hline Postoperative recovery care time & $223 \pm 81$ (CI: 205-241) & $216 \pm 95$ (CI: 165-269) & $222 \pm 82$ (CI: 205-238) & 0.771 \\
\hline Mean time without surgery time & $288 \pm 82$ (CI: $270-307)$ & $285 \pm 97$ (CI: 232-339) & $287 \pm(\mathrm{CI}: 278-333)$ & 0.908 \\
\hline${ }^{\dagger}$ Total time at operation department & $351 \pm 82.7$ (CI: 333-369) & $353 \pm 96.8$ (CI: $300-407)$ & $351 \pm 84.5$ (CI: $334-368)$ & 0.922 \\
\hline
\end{tabular}

Data were extracted from the single-center hospital's operation analysis program and are shown as mean \pm SD and CI

${ }^{\dagger}$ Total time at the operation department is calculated from patient start time at the operation theater to departure from the recovery care unit. Independent sample two-sided t-test, $P<0.05$ was considered significant

estimated time spent in the operation department, from start of operating theater time to patient discharge from the postoperative recovery unit, was comparable between the spinal and general anesthesia patients, respectively [351 \pm 82.7 (CI: 333369 ) vs. $353 \pm 96.8$ (CI: $300-407$ ) $\mathrm{min}, P=0.922]$. The overall time at the operation department (operation theater and recovery unit) was comparable between the single and the multicenter [351.2 \pm 84.5 (CI: 334.1-368.2) vs. $343 \pm 18.6$ (CI: 340.2-345.8) min, $P=0.351]$. Furthermore, no significant differences in the overall time at the operation department were detected when comparing spinal (350.8 \pm 82.7 vs. 339.4 $\pm 18.4, P=0.224)$ to general anesthesia $(353.1 \pm 96.8$ vs. $346.7 \pm 18.2, P=0.802$ ) for the single and the multicenter, respectively, indicating that differences in mode of anesthesia do not appear to drive differences in resource use related to surgery time when comparing low-volume sites with the highvolume site. The only significant observation detected was the comparison of overall time at the operation department between spinal and general anesthesia at the multicenter (339.4 \pm 18.4 vs. $346.7 \pm 18.2, P=0.009)$.

\section{Primary surgery cost comparison}

Disaggregated total costs for primary surgery at the single and multicenter using the Uphold mesh are shown in Table 3. Lower cost for surgery time was estimated at the multicenter compared to the single center $(\$ 1704 \pm 554$ vs. $\$ 1914 \pm 432$, $P<0.001)$. Costs for interventional anesthesia before and after surgery, including equipment and drugs used, were lower at the single center $(\$ 465 \pm 200$ vs. $\$ 587 \pm 166$ and $\$ 444 \pm 152$ vs. $\$ 482 \pm 60, P<0.001$ and 0.019 , respectively). Despite these differences, there was no significant difference between centers when the total operation theater $(\$ 3207 \pm 610$ vs. $\$ 3165 \pm 623, P=0.591)$ and recovery unit costs $(\$ 6684 \pm$ 2487 vs. $\$ 6,557 \pm 76, P=0.614$ ) were compared. Cost for hospital stay was higher at the multicenter than single center ( $\$ 2481 \pm 985$ vs. $\$ 2043 \pm 644, P<0.001)$. Total costs for the primary surgery were comparable between the single and multicenter $(\$ 13,561 \pm 2688$ vs. $\$ 13,867 \pm 1177$, respectively, $P=0.288)$.

\section{Follow-up cost comparison}

Follow-up costs for direct medical and surgical reinterventions after primary surgery and up to 2 months were doubled in the multicenter compared to single center use (mean $=\$ 497$ vs. $\$ 244, P=<0.001$ ) (Table 4 and Fig. 1). Costs included medical and surgical intervention for direct and indirect surgery complications and mesh-related complications in a total of 21 patients at the multicenter including urinary tract infection $n=2$, fever $n=1$, vaginal hematoma $n=2$, groin pain $n=7$, inferior pudendal artery embolization $n=1$ and reoperation and other intervention for mesh complications $n=5$ to be compared to six patients at the single center including urinary tract infection $n=3$, wound infection $n=1$ and reoperation for secondary bleeding $n=2$. Total costs estimated from primary surgery and up to 2 months after surgery were $\$ 14,364$ (CI: 14,187-14,540) vs. \$13,805 (CI: 13,263$14,363)$ for the multicenter and the single center, respectively $(P=0.054)$.

The estimated follow-up costs from 2 months to the next follow-ups (1 year for multicenter, 2 years for single center) were $\$ 1039$ vs. $\$ 128(P<0.001)$ for the multicenter vs. the single center, leading to a significant increase of total costs at the multicenter [\$15,403 (CI: 15,226-15,579) vs. $\$ 13,933$ (CI: 13,391-14,475), $P<001]$. The follow-up cost corresponded to reoperation for prolapse recurrence, $n=7$, and mesh revisions, $n=4$, at the multicenter compared to mesh revision, $n=1$, at the single center. 
Table 3 Costs for primary surgery with the Uphold mesh

\begin{tabular}{|c|c|c|c|c|c|c|c|}
\hline & \multicolumn{3}{|l|}{ Single center } & \multicolumn{3}{|l|}{ Multicenter } & \multirow[t]{2}{*}{$P$-value (cost differences) } \\
\hline & Mean \pm SD & $\mathrm{CI}$ & $n$ & Mean \pm SD & $\mathrm{CI}$ & $n$ & \\
\hline \multicolumn{8}{|l|}{ Operation costs } \\
\hline Surgery time & $1914 \pm 432$ & $1827-2002$ & 97 & $1704 \pm 554$ & $1621-1787$ & 173 & 0.001 \\
\hline Total surgery cost (including mesh) & $2796 \pm 432$ & $2709-2883$ & 97 & $2586 \pm 554$ & $2503-2697$ & 173 & 0.001 \\
\hline Anesthesia before surgery start ${ }^{\dagger}$ & $465 \pm 200$ & $425-505$ & 97 & $587 \pm 166$ & $562-612$ & 173 & $<0.001$ \\
\hline Anesthesia after surgery ended ${ }^{\dagger \dagger}$ & $444 \pm 152$ & $413-474$ & 97 & $482 \pm 60$ & $473-491$ & 173 & 0.019 \\
\hline Total operation theater cost & $3207 \pm 610$ & $3084-3330$ & 97 & $3165 \pm 623$ & $3071-3258$ & 173 & 0.591 \\
\hline Recovery unit cost & $6684 \pm 2487$ & $6183-7185$ & 97 & $6557 \pm 76$ & $6545-6568$ & 173 & 0.614 \\
\hline Total cost at operation department & $10,636 \pm 2450$ & $10,122-11,150$ & 97 & $10,505 \pm 616$ & $10,412-10,597$ & 173 & 0.618 \\
\hline Cost of hospital stay & $2043 \pm 644$ & $1913-2172$ & 97 & $2481 \pm 985$ & $2333-2629$ & 173 & $<0.001$ \\
\hline Total cost for spinal anesthesia & $13,503 \pm 2648$ & $12,921-14,084$ & 82 & $13,529 \pm 699$ & $13,380-13,678$ & 87 & 0.930 \\
\hline Total cost for general anesthesia & $13,878 \pm 2975$ & $12,230-15,525$ & 15 & $14,209 \pm 1440$ & $13,900-14,518$ & 86 & 0.678 \\
\hline Total costs of primary surgery ${ }^{\dagger \dagger \dagger}$ & $13,561 \pm 2688$ & $13,019-14,102$ & 97 & $13,867 \pm 1177$ & $13,691-14,187$ & 173 & 0.288 \\
\hline
\end{tabular}

Costs are shown as mean \pm SD and CI, in USD (\$)

${ }^{\dagger}$ and ${ }^{\dagger \dagger}$ Other costs for anesthesia including equipment and pharmacy are included

${ }^{\dagger \dagger}$ Total costs for primary surgery include costs for hospital stay and two standard outpatient visits

Analysis was done by independent sample two-sided t-test; $P<0.05$ was considered significant

At 5 year follow-up, there was further increase of follow-up costs by $\$ 1726$ at the multicenter compared to $\$ 777$ at the single center $(P<0.001)$. Additional follow-up costs at 5 years were because of reoperation for prolapse recurrence, $n=16$ patients at the multicenter and $n=6$ patients at the single center, and hysterectomy because of pain at the multicenter, $n=1$ patient. The total follow-up cost across 5 years was $\$ 3262$ at the multicenter compared to $\$ 1149$ at the single center $(P<0.001)$. In detail, mean follow-up cost for medical and surgery interventions including out-clinic and readmission because of surgery complications and mesh related complications was $\$ 1001$ at the multicenter vs. $\$ 372$ at the single center $(P<0.001)$. For reoperation of prolapse recurrence, the mean follow-up cost was $\$ 2260$ at the multicenter vs. $\$ 777$ at the single center $(P<0.001)$. Thus, the mean total cost per patient through 5 years was significantly higher at the multicenter compared to the single center [\$17,128 (CI: 16,952-17,305) vs. \$14,710 (CI: 14,16815,252), $P<0.001$ ] (Table 4 and Fig. 1).

\section{Effects of patient medical, socioeconomic and surgery characteristics on costs}

All results of multiple regression analysis on the impact of patient medical, socioeconomic and surgical characteristics on costs by type of site are shown in Table 5. Of patient medical and socioeconomic characteristics, only higher educational level at the single center ( $\beta$-coefficient -1307, CI: \$ $247--143$ and $P=0.029)$ inversely correlated to primary surgery and total costs at 5 years compared to the multicenter (difference in standardized $\beta$-coefficient -1.562).

From the surgical characteristics, more common use of general anesthesia in the multicenter setting was associated with an increase of costs of primary surgery and total costs at 5 years ( $\beta$-coefficient $669.5 \mathrm{CI}: \$ 304-1035, P<0.001$; difference in standardized $\beta$-coefficient of -1.883). Also, longer hospital stay in the multicenter setting was associated with an increase of costs of primary surgery and total costs at 5

Table 4 Total costs (\$) including accumulating follow-up costs at the single center $(n=97)$ and multicenter $(n=173)$

\begin{tabular}{|c|c|c|c|c|c|}
\hline & \multicolumn{2}{|l|}{ Single center } & \multicolumn{2}{|l|}{ Multicenter } & \multirow{2}{*}{$\begin{array}{l}P \text {-value (total } \\
\text { cost differences) }\end{array}$} \\
\hline & Total cost mean $(\mathrm{CI})$ & Follow-up cost & Total cost mean $(\mathrm{CI})$ & Follow-up cost & \\
\hline Primary surgery & $13,561(13,019-14,102)$ & & $13,867(13,691-14,187)$ & & 0.288 \\
\hline 2 months & $13,805(13,263-14,347)$ & 244 & $14,364(14,187-14,540)$ & 497 & 0.054 \\
\hline $1-2$ years & $13,933(13,391-14,475)$ & 128 & $15,403(15,226-15,579)$ & 1039 & $<0.001$ \\
\hline 5 years & $14,710(14,168-15,252)$ & 777 & $17,128(16,952-17,305)$ & 1726 & $<0.001$ \\
\hline
\end{tabular}

$P<0.05$ was considered significant, repeated measures ANOVA 
Fig. 1 Mean cost per patient for 5 years including costs for primary surgery with the Uphold mesh (green staple) and followups costs over 5 years after surgery (red staples). Costs are shown as mean with confidence interval (CI). $* * * P<0.001$, ANOVA repeated measures

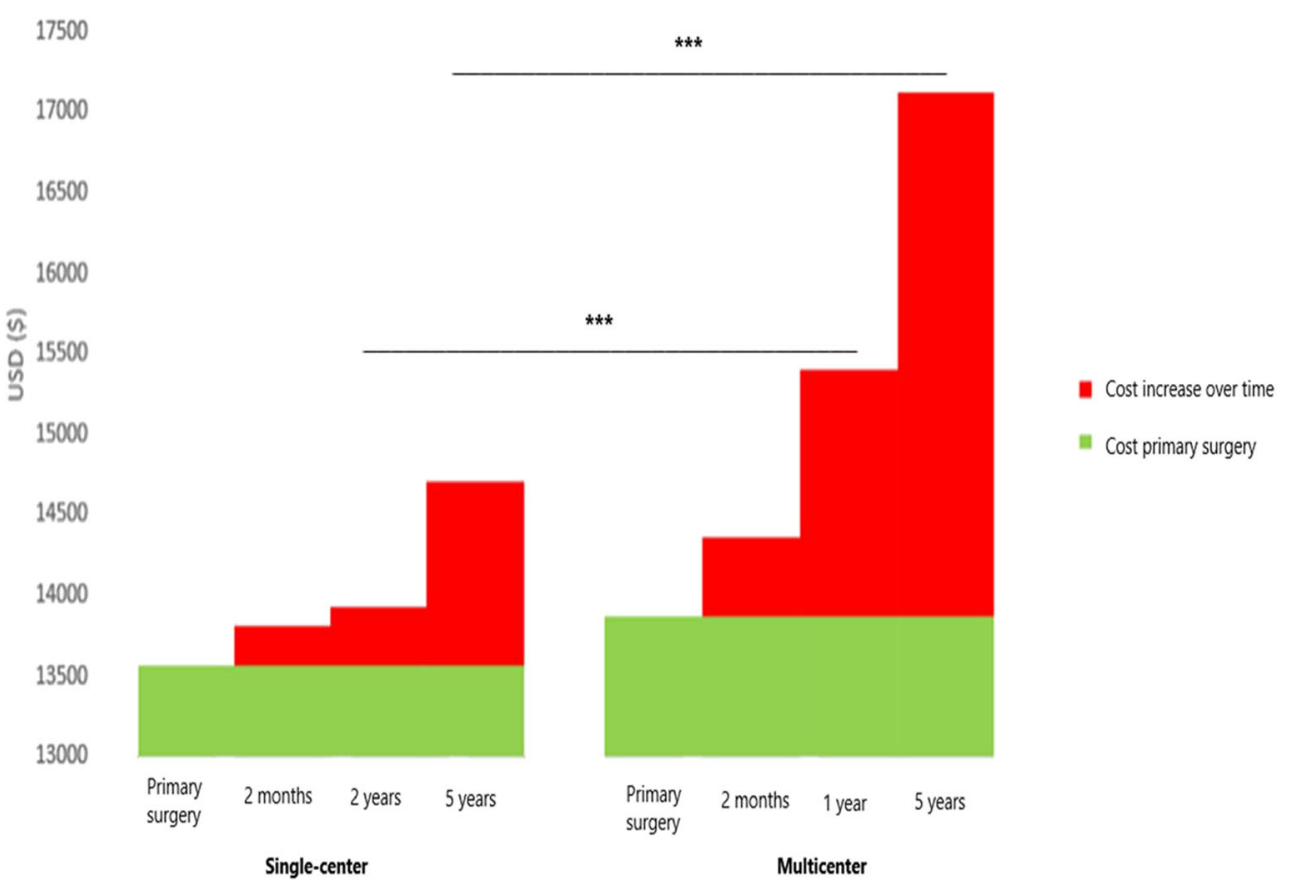

years ( $\beta$-coefficient 1593.9, CI: $\$ 1212-1976, P<0.001$ and difference in standardized $\beta$-coefficient of -3.025). However, shorter operation times in the multicenter setting correlated to lower primary surgery costs and total costs at 5 years $(\beta$-coefficient 38.5, CI: $\$ 28.2-\$ 48.8, P<0.001$; difference in standardized $\beta$-coefficient -3.042 ). No other characteristics had a significant influence on costs.

\section{Discussion}

This long-term assessment compared real-world healthcare costs between two separate cohort studies conducted in a high-volume single-center setting with multicenter low surgical volume using the same prolapse mesh kit in a standard surgical procedure. We found that costs for primary surgery were comparable between the single and multicenter and were comparable to previously estimated costs for vaginal surgery [16]. However, the long-term follow-up costs were more than two times higher in the multicenter setting, and single-site high-volume use reduced healthcare utilization costs in the long term. Surgery at a high-volume single center was associated with $65 \%$ lower follow-up costs and $14 \%$ lower total costs after 5 years compared to average costs at multicenter low-volume sites. This corresponds well with a previous study comparing the two cohorts that showed lower complication rates, re-intervention rates, lower risk for prolapse recurrence and significantly improved anatomical outcomes at the single compared to multicenter 5 years after primary surgery [3].

The difference in costs may partially be explained by more postoperative complications in the multicenter setting. The largest cost difference was found at 2 years after surgery where costs were eight times higher at the multicenter setting compared to the single center. This was mainly attributed to costs associated with re-operations for prolapse recurrence. At the end of follow-up at year 5, the cost difference in follow-up costs had decreased but remained significantly different and more than twice as large at the multicenter compared to the single center. Total costs 5 years after surgery were also significantly lower at the high-volume single site compared to the multicenter sites.

The impact of centralization of healthcare activities on healthcare costs has been the topic of many recent studies. Centralization and reliance on newer surgical techniques of total hip replacement (THR) services have been shown to reduce costs [10]. Undergoing radical cystectomy at a highvolume medical center was associated with improved outcomes and reduced costs [12]. High-volume hospitals have also been shown to provide more cost-effective neurosurgical care, and centralization of care at high-volume neurosurgical institutions may be a promising strategy for delivering higher value care, achieving better outcomes at lower costs [13]. Current treatment of ovarian cancer patients in semispecialized hospital settings is a cost-effective strategy [17]. Despite the mounting evidence that centralization of surgical procedures increases efficiency and cost-effectiveness, the evidence to support this change in practice is scarce and understudied in advanced pelvic organ prolapse surgery.

Accumulating evidence suggests that the Uphold vaginal mesh may be effective and safe if surgery is done at a high surgery volume unit [1-7]. In the present study, potential causes of cost reduction at the single high-volume center were 


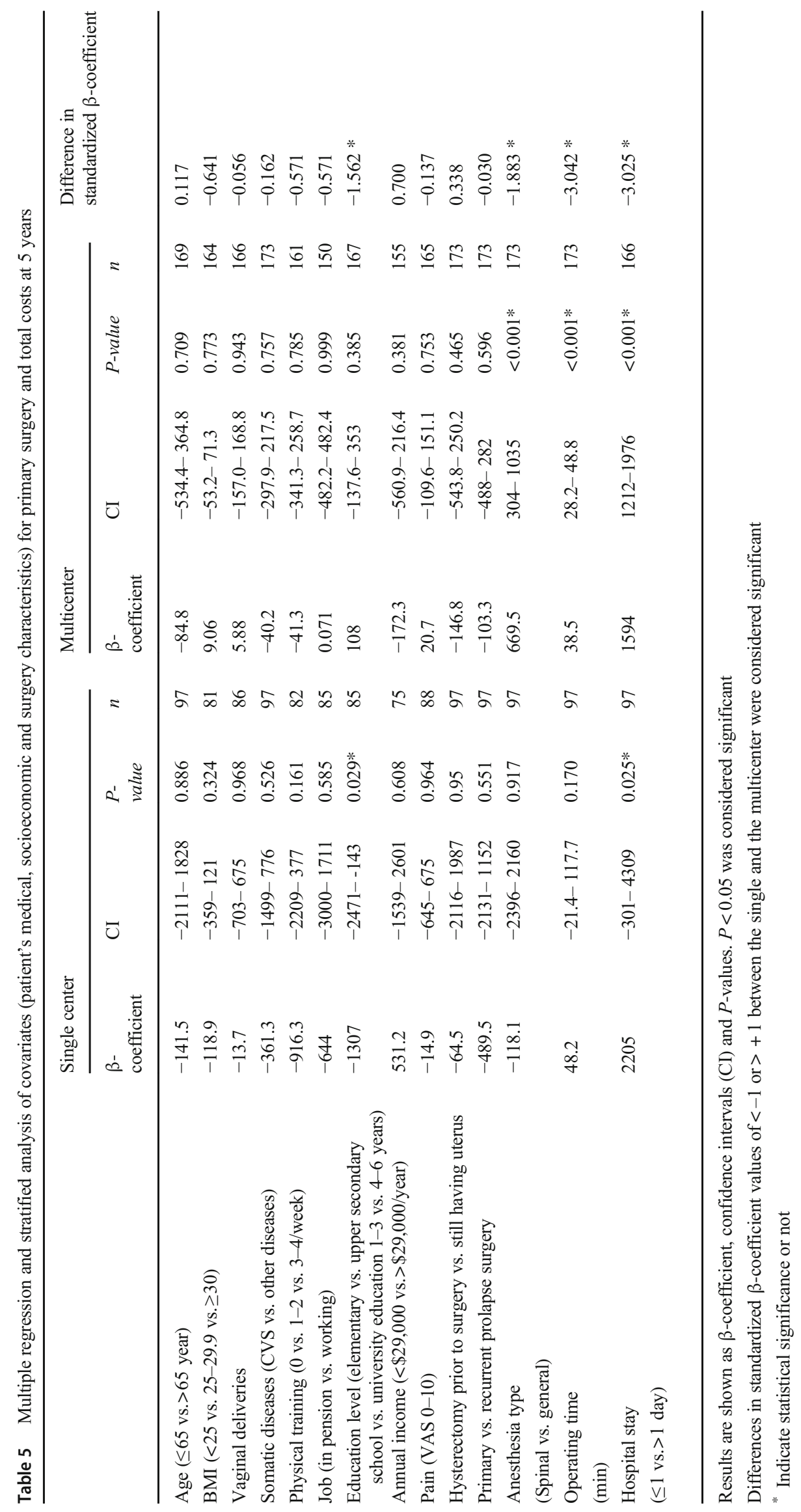


lower complication rates, lower rates of prolapse recurrence and fewer surgical and medical re-interventions. Other factors that may have increased the difference in costs despite the standardization of the procedure were the longer postoperative hospital stay and more frequent use of general anesthesia at the multicenter setting.

In search of predictors that may have influenced costs, we performed a multiple regression and stratified analysis of covariances. Only a higher educational level at the single center predicted lower costs of primary surgery as well as total costs at 5 years. In previous studies, the educational level had an impact on patient-reported disease-specific pelvic floor outcomes and was related to improved health-related quality of life compared to lower educational levels $[18,19]$. It is not known exactly how educational level affects costs, but one may assume that a higher educational level is associated with an overall healthier lifestyle, less obesity, less tobacco use and fewer comorbidities. Surgical characteristics including type of anesthesia, operating time and length of hospital stay independently influenced costs. Routine use of spinal anesthesia lowered the costs in favor of the high-volume center, whereas longer operating time, probably explained by more patients with prolapse recurrence at the time of primary mesh surgery, was an economic disadvantage at the single high-volume center.

Strengths of the study are use of real-world data on time and costs recorded at the hospitals, capturing resource use in clinical practice. The study populations were sufficiently large to determine the impact of the most important surgical factors on the costs associated with the procedure. Furthermore, classification of the procedure was homogeneous since all operations used an identical mesh kit and were performed in a standardized surgical manner.

Patient and surgeon allocation to high- and low-volume sites was not randomized, suggesting that several unmeasured effects may to some extent constitute a source of bias in estimates of costs associated to each setting. Another limitation was that the number of patients was insufficient for an analysis on the importance of individual experience and skill of the surgeons involved. Also, we did not have access to detailed socioeconomic characteristics of the patients to allow for an analysis of the influence of patient-attributed factors other than educational level. Since it has been argued that centralization should not be based solely on a minimum number of procedures, but rather on the multidisciplinary treatment of complex diseases [11], future studies should aim to control for these factors when comparing centralized single units to multicenter settings to fully understand the optimal setting for conducting mesh surgical procedures for pelvic organ prolapse. Additional ongoing studies are also warranted to compare the cost-effectiveness of vaginal mesh surgery to laparoscopic and robotic-assisted sacral colpopexy $[20,21]$ for apical pelvic organ prolapse.

\section{Conclusion}

In this long-term multivariate cost analysis study, we found that using a mesh kit for apical pelvic organ prolapse in a high surgical volume center was associated with reduced healthcare costs compared to a lower volume multiple-site setting. The cost reduction at the high surgical volume center increased over time because of the lower surgical and medical re-intervention rates for postoperative complication and recurrence. These results may guide future regulatory and health economic decisions when planning and implementing new healthcare routines in urogynecological surgery.

Acknowledgements Statistical analyses were performed in collaboration with statistician Fredrik Johansson, MSc, Department of Clinical Sciences Medical Library, Karolinska Institutet-Danderyd Hospital, Stockholm, Sweden. Extraction of unit costs were performed by PerOlof Carlbom, economist controller, Department of Obstetrics and Gynecology, and Department of Logopedics, Danderyd University Hospital, Stockholm, Sweden. Thanks to all members of the Nordic Transvaginal Mesh Group (Nordic TVM Group) for all surgeries performed in the multicenter surgery setting.

Author contributions Edward Morcos: principle investigator, study design, project development, statistical analysis and manuscript writing.

Christian Falconer: investigator, project development and critical revision of manuscript.

Emilie Toresson Grip: health economist, design of statistical analysis and critical revision of manuscript.

Kirk Geale: health economist, design of statistical analysis and critical revision of manuscript.

Katarina Hellgren: investigator, data collection and statistical analysis.

Georgios Poutakidis: investigator, patient examination, data collection and statistical analysis.

Daniel Altman: investigator, project development and critical revision of manuscript.

Funding Open access funding provided by Karolinska Institute. The single-center study was financially supported by hospital-administered funding (Clinical Research Unit, Department of Obstetrics and Gynecology, Danderyd Hospital) and received no external financial support. The multicenter study was supported by an investigator-initiated grant from Boston Scientific and grants from the Finnish Medical Foundation and the Swedish Research Council.

\section{Declarations}

Conflicst of interest None.

Financial disclosure Edward Morcos: None.

Christian Falconer has received speaking and advisory honoraria from Boston Scientific and Johnson \& Johnson.

Emilie Toresson Grip is an employee of Quantify Research AB.

Kirk Geale is an employee, board member and options holder of Quantify Research AB.

Katarina Hellgren: None.

Georgios Poutakidis: None. 
Daniel Altman has received speaking and advisory honoraria from Gedeon Richter, Pfizer, Astellas, Invent Medic and Gynecare.

Ethical approval The studies were approved by The Stockholm Regional Board of Ethics at the Karolinska Institutet, Stockholm, Sweden, and ethic review committees in the respective countries and were registered at www.clinicaltrials.gov; the single-center study NCT03077490 and the multicenter study NCT01823055.

Open Access This article is licensed under a Creative Commons Attribution 4.0 International License, which permits use, sharing, adaptation, distribution and reproduction in any medium or format, as long as you give appropriate credit to the original author(s) and the source, provide a link to the Creative Commons licence, and indicate if changes were made. The images or other third party material in this article are included in the article's Creative Commons licence, unless indicated otherwise in a credit line to the material. If material is not included in the article's Creative Commons licence and your intended use is not permitted by statutory regulation or exceeds the permitted use, you will need to obtain permission directly from the copyright holder. To view a copy of this licence, visit http://creativecommons.org/licenses/by/4.0/.

\section{References}

1. Rahkola-Soisalo P, Mikkola TS, Altman D, Falconer C, Nordic TVM Group. Pelvic organ prolapse repair using the uphold vaginal support system: 5-year follow-up. Female Pelvic Med Reconstr Surg. 2019;25(3):200-5.

2. Gillor M, Langer S, Dietz HP. A long-term comparative study of uphold $^{\mathrm{TM}}$ transvaginal mesh kit against anterior colporrhaphy. Int Urogynecol J. 2020;31(4):793-7.

3. Falconer C, Altman D, Poutakidis G, Rahkola-Soisalo P, MikkolaT Morcos E. Long-term outcomes of pelvic organ prolapse repair using a mesh-capturing device when comparing single- versus multicenter use. Arch GynecolObstet. 2020. https://doi.org/10.1007/ s00404-020-05764-3.

4. Jeffery ST, Kortz BS, Muavha D, Stolwijk NN, Ras L, Roovers JWR. Morbidity of a single incision transvaginal mesh to correct apical prolapse. J Minim Invasive Gynecol. 2019;26(7):1282-7.

5. Allegre L, Debodinance P, Demattei C, Fabbro Peray P, Cayrac M, Fritel X, Courtieu C, Fatton B, de Tayrac R. Clinical evaluation of the uphold LITE mesh for the surgical treatment of anterior and apical prolapse: a prospective, multicentre trial. Neurourol Urodyn. 2019;38(8):2242-9.

6. Morcos E, Altman D, Hunde D, Falconer C, Nordic TVM group. Comparison of single- versus multicenter outcomes for pelvic organ prolapse repair using a mesh-capturing device. IntUrogynecol J. 2018;29(1):91-7.

7. de Tayrac R, Faillie JL, Gaillet S, Boileau L, Triopon G, Letouzey $\mathrm{V}$. Analysis of the learning curve of bilateral anterior sacrospinous ligament suspension associated with anterior mesh repair. Eur J Obstet Gynecol Reprod Bio. 2012;165(2):361-5.

8. de Tayrac R, Sentilhes L. Complications of pelvic organ prolapse surgery and methods of prevention. Int Urogynecol J. 2013;24(11): 1859-72.
9. Xu K, Soucat A, Kutzin J, et al. Public spending on health: a closer look at global trends. Geneva: World Health Organization; 2018 (WHO/HIS/HGF/HFWorkingPaper/18.3). Licence: CC BY-NCSA 3.0 IGO.

10. Goldstein JP, Babikian GM, Rana AJ, Mackenzie JA, Millar A. The cost and outcome effectiveness of total hip replacement: technique choice and volume-output effects matter. Appl Health Econ Health Policy. 2016;14(6):703-18.

11. Vonlanthen R, Lodge P, Barkun JS, Farges O, Rogiers X, Soreide K, Kehlet H, Reynolds JV, Käser SA, Naredi P, Borel-Rinkes I, Biondo S, Pinto-Marques $\mathrm{H}$, Gnant M, Nafteux P, Ryska M, Bechstein WO, Martel G, Dimick JB, Krawczyk M, Oláh A, Pinna AD, Popescu I, Puolakkainen PA, Sotiropoulos GC, Tukiainen EJ, Petrowsky H, Clavien PA. Toward a consensus on centralization in surgery. Ann Surg. 2018;268(5):712-24.

12. Gorin MA, Kates M, Mullins JK, Pierorazio PM, Matlaga BR, Schoenberg MP, Bivalacqua TJ. Impact of hospital volume on perioperative outcomes and costs of radical cystectomy: analysis of the Maryland Health Services Cost Review Commission database. Can J Urol. 2014;21(1):7102-7.

13. Yoon JS, Tang OY, Lawton MT. Volume-cost relationship in neurosurgery: analysis of $12,129,029$ admissions from the national inpatient sample. World Neurosurg. 2019;129:e791-802. https://doi. org/10.1016/j.wneu.2019.06.034.

14. Altman D, Mikkola TS, Bek KM, Rahkola-Soisalo P, Gunnarsson J, Engh ME, Falconer C, Nordic TVM group. Pelvic organ prolapse repair using the uphold ${ }^{\mathrm{TM}}$ vaginal support system: a 1-year multicenter study. IntUrogynecol J. 2016;27(9):1337-45.

15. Bump RC, Mattiasson A, Bø K, Brubaker LP, DeLancey JO, Klarskov P, Shull BL, Smith AR. The standardization of terminology of female pelvic organ prolapse and pelvic floor dysfunction. Am J Obstet Gynecol. 1996;175(1):10-7.

16. Lua LL, Vicente ED, Pathak P, Lybbert D, Dandolu V. Comparative analysis of overall cost and rate of healthcare utilization among apical prolapse procedures. Int Urogynecol J. 2017;28(10):1481-8.

17. Greving JP, Vernooij F, Heintz AP, van der Graaf Y, Buskens E. Is centralization of ovarian cancer care warranted? A costeffectiveness analysis Gynecol Oncol. 2009;113(1):68-74.

18. Altman D, Geale K, Falconer C, Morcos E. A generic health-related quality of life instrument for assessing pelvic organ prolapse surgery: correlation with condition-specific outcome measures. Int Urogynecol J. 2018;29(8):1093-9.

19. Torvinen S, Färkkilä N, Sintonen H, Saarto T, Roine RP, Taari K. Health-related quality of life in prostate cancer. Acta Oncol. 2013;52(6):1094-101.

20. Gutman RE, Rardin CR, Sokol ER, Matthews C, Park AJ, Iglesia CB, Geoffrion R, Sokol AI, Karram M, Cundiff GW, Blomquist JL, Barber MD. Vaginal and laparoscopic mesh hysteropexy for uterovaginal prolapse: a parallel cohort study. Am J Obstet Gynecol. 2017;216(1):38.e1-38.e11. https://doi.org/10.1016/j. ajog.2016.08.035.

21. Ng-Stollmann N, Fünfgeld C, Gabriel B, Niesel A. The international discussion and the new regulations concerning transvaginal mesh implants in pelvic organ prolapse surgery. Int Urogynecol J. 2020;31(10):1997-2002.

Publisher's note Springer Nature remains neutral with regard to jurisdictional claims in published maps and institutional affiliations. 